\title{
Peran Ekosistem Hutan Mangrove Sebagai Habitat Untuk Organisme Laut
}

\author{
Karimah $^{1}$ \\ ${ }^{1}$ Mahasiswa Program Studi Magister Pendidikan IPA Universitas Mataram \\ Email : karimah@gmail.com
}

\begin{abstract}
Abstrak
Tulisan ini menjelaskan tentang peran ekosistem hutan mangrove sebagai habitat untuk organisme laut dengan menggunaan analisis diskriptif. Data diambil dari literatur-literatur terkait yang kemudian didiskripsikan lebih lanjut. Data yang diperoleh menunjukkan bahwa hutan mangrove di Indonesia diperkirakan mencakup area seluas 4,25 juta hektar, hanya sekitar 2\% dari seluruh wilayah daratan, namun nilai ekonomi dan lingkungannya tidak boleh di bawah perkiraan, oleh karena itu kehadirannya harus dijaga. Sebagai zona transisi antara ekosistem terestrial dan laut, ekosistem mangrove telah lama dikenal memiliki banyak fungsi dan merupakan penghubung penting dalam menjaga keseimbangan biologis ekosistem pesisir. Ekosistem hutan mangrove merupakan habitat penting bagi organisme laut. Umumnya didominasi oleh moluska dan krustasea. Moluska ini terdiri terutama dari Gastropoda dan selanjutnya didominasi oleh dua keluarga, yaitu Potamidae dan Ellobiidae. Sedangkan untuk krustasea, terutama terdiri dari Brachyura. Beberapa fauna mangrove juga dikenal sebagai bahan habis pakai dan secara ekonomi penting seperti Terebralia palustris, Telescopium telescopium (Gastropoda), Anadara kuno, Coaxans polymesoda, Ostrea cucullata (Bivalvia), dan Scylla serrate, S. olivacea, Portunus pelagicus, Epixanthus dentatus, Labnanium politum (Crustacea).
\end{abstract}

Kata kunci : hutan mangrove, ekosistem mangrove, moluska

\begin{abstract}
This paper describes the role of the mangrove forest ecosystem as a habitat for marine organisms by using descriptive analysis. The data are drawn from related literatures which are further described. The data obtained indicate that mangrove forests in Indonesia are estimated to cover an area of 4.25 million hectares, only about $2 \%$ of the entire land area, but its economic and environmental value should not be underestimated, therefore its presence must be maintained. As a transition zone between terrestrial and marine ecosystems, the mangrove ecosystem has long been known to have many functions and is an important link in maintaining the biological balance of coastal ecosystems. The mangrove forest ecosystem is an important habitat for marine organisms. Generally dominated by molluscs and crustaceans. This mollusc consists mainly of Gastropods and is further dominated by two families, namely Potamidae and Ellobiidae. As for crustaceans, mainly consisting of Brachyura. Some mangrove fauna are also known as economical and economically important materials such as Terebralia palustris, Telescopium telescopium (Gastropoda), ancient Anadara, Coaxans polymesoda, Ostrea cucullata (Bivalvia), and Scylla serrate, S. olivacea, Portunus pelagicus, Epixanthus dentatus, Labnanium politic (Crustacea).
\end{abstract}

Keywords: mangrove forest, mangrove ecosystem, mollusk, 


\section{Pendahuluan}

Indonesia merupakan suatu negara kepulauan yang terdiri dari 13.667 pulau dan mempunyai wilayah pantai sepanjang 54.716 kilometer.Wilayah pantai (pesisir) ini banyak ditumbuhi hutan mangrove. Luas hutan mangrove di Indonesia sekitar 4.251.011,03 hektar dengan penyebaran: 15,46 persen di Sumatera, 2,35 persen di Sulawesi, 2,35 persen di Maluku, 9,02 persen di Kalimantan, 1,03 persen di Jawa, 0,18 persendi Bali dan Nusa Tenggara, dan 69,43 persen di Irian Jaya (Fao, 1990 dalam Hainim, 1996). Namun, menurut Cifor (2012), luas hutan mangrove di Indonesia telah mengalami penurunan $30-50 \%$ pada setengah abad terakhir ini karena pembangunan daerah pesisir, perluasan pembangunan tambak, abarasi air laut, dan penebangan yang berlebihan. Sedangkan berdasarkan data Kementrian Kehutanan (2013), Hutan mangrove di Indonesia tersebar di beberapa provinsi di berbagai gugusan kepulauan. Luasan hutan mangrove di Indonesia lebih kurang 3,7 juta hektar yang merupakan hutan mangrove terluas yang ada di Asia dan bahkan di dunia. Menurut catatan Statistik Kehutanan Tahun 1993 NTB mempunyai luas kawasan hutan sebesar 1.063.273,20 ha., dan 160.878,50 ha $(15,13 \%)$ berada di pulau Lombok. Luas hutan mangrove dalam Statistik Kehutanan NTB Tahun 1993, sebesar 49.174 ha. (Chaniago dan Hayashi , 1994).

Menurut Imran (2016), ekosistem hutan mangrove merupakan salah satu ekosistem yang memiliki produktivitas tinggi dibandingkan ekosistem lain dengan dekomposisi bahan organik yang tinggi, dan menjadikannya sebagai mata rantai ekologis yang sangat penting bagi kehidupan mahluk hidup yang berada di perairan sekitarnya. Materi organik menjadikan hutan mangrove sebagai tempat sumber makanan dan tempatasuhan berbagai biota seperti ikan, udang dan kepiting. Produksi ikan dan udang di perairan laut sangat bergantung dengan produksi serasah yang dihasilkan oleh hutan mangrove. Berbagai kelompok moluska ekonomis juga sering ditemukan berasosiasi dengan tumbuhan penyusun hutan mangrove. Sedangkan Bruno, $d k k$ (1998) menyatakan bahwa hutan mangrove merupakan jenis maupun komunitas tumbuhan yang tumbuh di daerah pasang surut. Selain itu, hutan mangrove mempunyai karakteristik yang unik dibandingkan dengan formasi hutan lainnya. Keunikan hutan tersebut terlihat dari habitat tempat hidupnya, juga keanekaragaman flora, yaitu: Avicennia, Rhizophora, Bruguiera, dan tumbuhan lainnya yang mampu bertahan hidup disalinitas air laut, dan fauna yaitu kepiting, ikan, jenis Molusca, dan lain-lain. Hutan mangrove juga memiliki fungsi ekonomi, ekologi, dan sosial. Fungsi ekonomi yang ada di hutan mangrove yaitu penghasil kebutuhan rumah tangga, penghasil keperluan industri, dan penghasil bibit. Fungsi ekologisnya yaitu sebagai pelindung garis pantai, mencegah intrusi air laut, sebagai habitat berbagai jenis burung, dan lain-lain (Kustanti, 2011). Namun Saenger et al. (1983) menyatakan bahwa, jenis tumbuhan mangrove di seluruh dunia adalah sekitar 60 jenis.

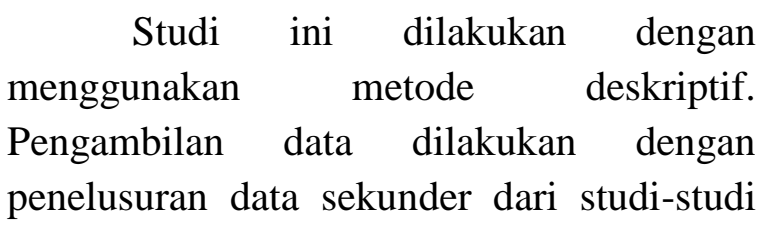


terkait. Data yang diperlukan adalah data yang terkait dengan peranan mangrove sebagai habitat berbagai organisme yang ada di laut.

\section{Pembahasan}

\subsection{Faktor yang Mempengaruhi Eksistensi Hutan Mangrove}

Sebagai daerah peralihan antara laut dan daratan, hutan mangrove mempunyai gradien sifat lingkungan yang sangat ekstrim. Pasang- surut air laut menyebabkan terjadinya perubahan beberapa faktor lingkungan yang besar, terutama suhu dan salinitas. Oleh karena itu, hanya beberapa jenis tumbuhan yang memiliki daya toleransi yang tinggi terhadap lingkungan yang ekstrim tersebut saja yang mampu bertahan hidup dan berkembang didalamnya. Kondisi yang terjadi tersebut juga menyebabkan rendahnya keanekaragaman jenis, namun disisi lain kepadatan populasi masing-masing jenis umumnya tinggi.

Walaupun habitat hutan mangrove bersifat khusus, namun masingmasing jenis tumbuhan memiliki kisaran ekologi tersendiri, sehingga kondisi ini menyebabkan terbentuknya berbagai macam komunitas dan bahkan permintakatan atau zonasi, sehingga kompetisi jenis berbeda dari satu tempat ke tempat lainnya. Munculnya fenomena permintakatan yang terjadi pada hutan mangrove tersebut sangat berkaitan erat dengan beberapa faktor, antara lain adalah tipe tanah, keterbukaan areal mangrove dari hempasan ombak, salinitas dan pengaruh pasang- surut (Soerianegara, 1971; Champman, 1976; Kartawinata \& Waluyo, 1977). Pengaruh tipe tanah atau substrat tersebut, sangat jelas terlihat pada jenis Rhizophora, misalnya pada tanah lumpur yang dalam dan lembek akan tumbuh dan didominasi oleh Rhizophora mucronata yang kadangkadang tumbuh berdampingan dengan Avicennia marina, kemudian untuk Rhizophora stylosa lebih menyukai pada pantai yang memiliki tanah pasir atau pecahan terumbu karang, dan biasanya berasosiasi dengan jenis Sonnerafia alba. Sedangkan untuk jenis Rhizophora apiculata hidup pada daerah transisi.

Selain tipe tanah, kondisi kadar garam atau salinitas pada substrat juga mempunyai pengaruh terhadap sebaran dan terjadinya permintakatan. Berbagai macam jenis tumbuhan mangrove mampu bertahan hidup pada salinitas tinggi, namun jenis Avicennia merupakan jenis yang mampu hidup bertoleransi terhadap kisaran salinitas yang sangat besar. Macnae (1968) menyebutkan bahwa Avicennia marina mampu tumbuh pada salinitas sangat rendah sampai $90 \%$, sedangkan Sonneratia sp. umumnya hidup pada salinitas yang tinggi, kecuali Sonnerafia casiolaris (sekitar 10 \%o). Jenis Bruguiera sp biasanya tumbuh pada salinitas maksimum sekitar 25\%o, sedangkan jenis Ceriops tagal, Rhizophora mucronafa dan Rhizophora stylosa mampu hidup pada salinitas yang relatif tinggi.

Disamping faktor-faktor tersebut di atas, pasang-surut air laut juga mempunyai pengaruh terhadap jenis tumbuhan mangrove yang tumbuh pada suatu daerah. Watson dalam Kartawinata, $d d k$ (1979) memberikan gambaran tentang lima kelas genangan yang merupakan korelasi antara tingginya genangan air pasang dan 
lama genangan, dengan jenis tumbuhan mangrove. Adapun klasifikasi kelas genangan tersebut adalah sebagai berikut:

1) Kawasan pantai digenangi oleh setiap air pasang (all high tides). Di tempat seperti ini jarang jenis mangrove yang mampu hidup, kecuali Rhizophora mucronata.

2) Kawasan pantai digenangi oleh air pasang agak besar (medium high tide). Di tempat seperti ini yang muncul adalah jenis Avicennia sp. dan Sonneratia sp.

3) Kawasan pantai digenangi oleh air pasang rata-rata (normal high tide). Tempat ini mencakup sebagian besar hutan mangrove, yang ditumbuhi jenis Rhizopora mucronata, Rhizophora apiculata, Ceriops tagal dan Bruguiera parviflora.

4) Kawasan pantai digenangi oleh air pasang perbani (spring tides). Di daerah ini jenis tumbuh jenis Bruguiera sp., dan umumnya adalah Bruguiera cylindrica membentuk tegakan murni, namun kadang-kadang pada areal yang baik drainasinya ditumbuhi oleh Bruguiera parviflora dan Bruguiera sexangula.

5) Kawasan pantai yang kadangkadang digenangi oleh pasang tertinggi (excep tional or equinoctial tides). Di tempat ini Bruguiera gymnorrhiza berkembang dengan baik, dan kadang berasosiasi dengan paku-pakuan Acrostichum sp.

\subsection{Peranan dan Fungsi Ekosistem}

\section{Mangrove}

Menurut Saenger (1981) dalam Anwar, dkk (1984) salah satu fungsi ekosistem mangrove adalah sebagai Fungsi biologi, yaitu sebagai dearah pasca larva dan yuwana jenis jenis ikan tertentu dan menjadi habitat alami berbagai jenis biota dengan produktivitas yang tinggi, serta bersarangnya burung-burung besar.

Ekosistem mangrove merupakan ekosistem peralihan antara darat dan laut yang dikenal memiliki peran dan fungsi sangat besar. Secara ekologis mangrove memiliki fungsi yang sangat penting dalam memainkan peranan sebagai mata rantai makanan di suatu perairan, yang dapat menumpang kehidupan berbagai jenis ikan, udang dan moluska. Perlu diketahui bahwa hutan mangrove tidak hanya melengkapi pangan bagi biota aquatik saja, akan tetapi juga dapat menciptakan suasana iklim yang kondusif bagi kehidupan biota aquatik, serta memiliki kontribusi terhadap keseimbangan siklus biologi di suatu perairan. Kekhasan tipe perakaran beberapa jenis tumbuhan mangrove seperti Rhizophora sp., Avicennia sp. dan Sonneratia sp. dan kondisi lantai hutan, kubangan serta aluralur yang saling berhubungan merupakan perlidungan bagi larva berbagai biota laut. Kondisi seperti ini juga sangat penting dalam menyediakan tempat untuk bertelur, pemijahan dan pembesarkan serta tempat mencari makan berbagai macam ikan dan udang kecil, karena suplai makanannya tersedia dan terlindung dari ikan pemangsa. Ekosistem mangrove juga berperan sebagai habitat bagi jenis-jenis ikan, kepiting dan kerang-kerangan yang mempunyai nilai ekonomi tinggi.

Dilihat dari aspek fisik, hutan mangrove mempunyai peranan sebagai pelindung kawasan pesisir dari hempasan angin, arus dan ombak dari laut, serta berperan juga sebagai benteng dari pengaruh 
banjir dari daratan. Tipe perakaran beberapa jenis tumbuhan mangrove (pneumatophore) tersebut juga mampu mengendapkan lumpur, sehingga memung- kinkan terjadinya perluasan areal hutan mangrove. Disamping itu, perakaran jenis tumbuhan mangrove juga mampu berperan sebagai perangkap sedimen dan sekaligus mengendapkan sedimen, yang berarti pula dapat melindungi ekosistem padang lamun dan terumbu karang dari bahaya pelumpuran. Terciptanya keutuhan dan kelestarian ketiga ekosistem dari bahaya kerusakan tersebut, dapat menciptakan suatu ekosistem yang sangat luas dan komplek serta dapat memelihara kesuburan, sehingga pada akhirnya dapat menciptakan dan memberikan kesuburan bagi perairan kawasan pantai dan sekitarnya.

\subsection{Organisme Laut Penghuni Hutan Mangrove}

Pengetahuan tentang organism laut penghuni hutan mangrove di Indonesia hingga saat ini masih dirasakan sangat kurang, dan kalaupun ada orientasinya bukan pada aspek ekologinya, akan tetapi penekanannya cenderung pada aspek taksonominya.

Sebagaimana fenomena yang terjadi pada hutan mangrove yakni dicirikan dengan adanya zonasi atau permintakatan oleh jenis tumbuhan yang dominan, maka fauna penghuni hutan mangrove pun juga memperlihatkan adanya permintakatan. Terkait dengan sifat fauna yang pada umumnya sangat dinamis, maka batasan zonasi yang terjadi pada fauna penghuni mangrove kurang begitu jelas
(Kartawinata $d k k$. 1979). Penyebaran fauna penghuni hutan mangrove memperlihatkan dua cara, yaitu penyebaran secara vertical dan secara horisontal. Penyebaran secara vertikal umumnya dilakukan oleh jenis fauna yang hidupnya menempel atau melekat pada, akar, cabang maupun batang pohon mangrove, misalnya jenis Liftorina scabra, Nerita albicilla, Menetaria annulus dan Melongena galeodes (Budiman \& Darnaedi, 1984; Soemodihardjo, 1977). Sedangkan penyebaran secara horizontal biasanya ditemukan pada jenis fauna yang hidup pada substrat, baik itu yang tergolong infauna, yaitu fauna yang hidup dalam lubang atau dalam substrat, maupun yang tergolong epifauna, yaitu fauna yang hidup bebas di atas substrat. Distribusi fauna secara horisontal pada areal hutan mangrove yang sangat luas, biasanya memperlihatkan pola permintakatan jenis fauna yang dominan dan sejajar dengan garis pantai. Permintakatan yang terjadi di daerah ini sangat erat kaitannya dengan perubahan sifat ekologi yang sangat ekstrim yang terjadi dari laut ke darat. Kartawinata \& Soemodihardjo (1977) menyatakan bahwa, permintakatan fauna hanya terlihat pada hutan mangrove sangat iuas, tetapi tidak terlihat pada hutan mangrove yang ketebalannya sangat rendah.

Secara ekologis, jenis moluska penghuni mangrove memiliki peranan yang besar dalam kaitannya dengan rantai makanan di kawasan mangrove, karena disamping sebagai pemangsa detritus, moluska juga berperan dalam merobek atau memperkecil serasah yang baru jatuh. Perilaku moluska jenis Telebraria palustris dan beberapa moluska lainnya dalam 
memecah atau menghancurkan serasah man- grove untuk dimakan, namun disisi lain sangat besar artinya dalam mempercepat proses dekomposisi serasah yang dilakukan mikrorganime akan lebih cepat. Disamping membantu dalam proses dekomposisi, beberapa fauna kepiting juga membantu dalam penyebaran seedling dengan cara menarik propagul kedalam lubang tempat persembunyiannya ataupun pada tempat yang berair. Aktifitas kepiting ini dampaknya sangat baik dalam kaitannya dengan distribusi dan kontribusi pertumbuhan dari seedling mangrove dari jenis Rhizophora sp, Bruguiera sp. dan Ceriops sp., terutama pada daerah yang sudah atau mulai terjadi konversi hutan mangrove.

Fauna moluska yang hidup sebagai penghuni hutan mangrove di Indonesia umumnya didominasi oleh Gastropoda, yaitu sekitar 61 jenis, sedangkan dari kelas Bivalvia hanya sekitar 9 jenis saja. Dari fauna Gastropoda penghuni mangrove yang memiliki penyebaran yang sangat luas adalah Littorina scabra, Terebralia palustris, T. sulcata dan Cerithium patalum. Sedangkan jenis yang memiliki daya adaptasi yang tinggi terhadap lingkungan yang sangat ekstrim adalah Littorina scabra, Crassostrea cacullata dan Enigmonia aenigmatica (Budiman \& Darnaedi, 1984). Selanjutnya disebutkan pula bahwa dari sebanyak Gastropoda penghuni hutan mangrove tersebut beberapa diantaranya dapat dimanfaatkan untuk dikonsumsi masyarakat sekitar mangrove, antara lain adalah jenis Terebralia palustris dan Telescopium telescopium. Sedangkan kelas Bivalvia yang dikonsumsi masyarakat adalah jenis Polymesoda coaxans, Anadara antiquata dan Ostrea cucullata Kelas Crustacea yang ditemukan pada ekosistem hutan mangrove adalah sebanyak 54 jenis, dan umumnya didominasi oleh jenis kepiting (Brachyura) yang dapat dikategorikan sebagai golongan infauna, sedangkan beberapa jenis udang (Macrura) yang ditemukan pada ekosistem mangrove sebagian besar hanya sebagai penghuni sementara. Dari beberapa penelitian yang dilakukan di berbagai tempat menunjukkan bahwa famili Grapsidae merupakan penyusun utama fauna Crustacea hutan mangrove (Soemodihardjo 1977, Budiman dkk. 1977). Jenis Thalassina anomala merupakan jenis udang lumpur sebagai penghuni setia hutan mangrove, karena udang ini hidup dengan cara membuat lubang dan mencari makan hanya disekitar sarang tersebut. Sedangkan pada hutan mangrove bersubstrat lumpur agak pejal, umumnya didominasi $U c a$ dusumeri. Jenis lain yang muncul pada substrat tersebut adalah Uca lactea, $U$. vocans, U. signatus dan U. conso-brinus. Diantara kepiting mangrove yang mempunyai nilai ekonomis dan dikonsumsi masyarakat adalah Scylla serrata, $S$. olivacea, Portunus pelagicus, Epixanthus dentatus dan Labnanium politum.

\section{Kesimpulan}

Berdasarkan hasil studi yang telah dilakukan dengan menggunakan metode deskriptif dan studi studi literature, maka dapat disimpulkan bahwa ekosistem hutan mangrove merupakan habitat penting bagi organisme laut. Umumnya didominasi oleh moluska dan krustasea. Moluska ini terdiri 
terutama dari Gastropoda dan selanjutnya didominasi oleh dua keluarga, yaitu Potamidae dan Ellobiidae. Sedangkan untuk krustasea, terutama terdiri dari Brachyura. Beberapa hewan yang hidup di hutan mangrove juga dikenal sebagai bahan habis pakai dan secara ekonomi penting seperti Terebralia palustris, Telescopium telescopium (Gastropoda), Anadara kuno, Coaxans polymesoda, Ostrea cucullata (Bivalvia), dan Scylla serrate, S. olivacea, Portunus pelagicus, Epixanthus dentatus, Labnanium politum (Crustacea), oleh sebab itu hutan mangrove harus dijaga kelestariannya.

\section{Daftar Pustaka}

Al Hakim, I., A. L. Devi dan Siswanto, 1982. Studi pendahuluan susunan jenis moluska dan krustasea di Tanjung Karawang, Jawa Barat Pros. Sem. II Ekos. Hut. Mangrove. MAB-LIPI: 224-231.

Arief, A. 2003. Hutan Mangrove Fungsi dan Manfaatnya..Yogyakarta.

Budiman, A., M. Djajasasmita dan F. Sabar, 1977. Penyebaran keong dan kepeting hutan bakau Wai Sekampung, Lampung. Ber. Biol. 2:1-24.

Budiman, A. dan D. Darnaedi, 1984. Struktur komunitas moluska di hutan mangrove Morowali, Sulawesi Tengah. Pros. Sem. II Ekos. Mangrove. MAB- LIPI: 175182.

Center for International Forestry Research (Cifor). 2012. Mangrove adalah salah satu hutan terkaya karbon di kawasan tropis. Jurnal brief. 12(1):1.

Djamali, A. 1990 . Telah ekologi kelimpahan juwana udang jerbung (Paneus merguensisi de Man) di perairan sekitar mangrove Sungai Donan, Jawa Tengah. Pros. Sem. IV Ekos. Mangrove. MAB-LIPI: 174-182.
Imran, Ali dan Efendi, Ismail.2016. Inventarisasi Mangrove di Pesisir Pantai Cemare Lombok Barat. JUVE; vol. I.

Fao, Rome. 1983. Hutching, $\mathrm{P}$ and P.Saenger.Ecology of Mangroves. University of Queensland, London. 1987 Mann, K.H. Ecology of Coastal Waters.

Kartawinata, K. and E. B. Waluyo, 1977. A preliminary study of the mangrove forest on Pulau Rambut, Jakarta Bay. Mar. Res. Indon. 18:119-129.

Kartawinata, K., S. Adisoemardjo, S. oemodihardjo dan I. G. M. Tantra. 1979. Status pengetahuan hutan bakau di Indonesia Pros. Sem. Ekos. Hutan Mangrove: 21-39.

Kementerian Kehutanan. 2013. Luasan hutan mangrove di Indonesia. Diunduh pada tanggal $14 \quad$ November 2017. hhtp://kementerian kehutanan.com.

Kustanti, A. 2011. Manajemen Hutan Mangrove. Buku. IPB Press. Bogor. 248 p.

Saenger, P., E. J. Hegerl and J. D. S. DA Vie 1983. Global status of mangrove ecosystems. By the working group on mangrove ecosystems on the IUCN Commission on Ecology. The environmentalist, Vol. 3. Supplement No.: p. 88.

Soemodihardjo, S. dan W. Kastoro. 1977. Notes on Telebraria palustris (Gastropoda) from the coral Islands in the Jakarta Bay area. Mar. Res. Indonesia. 18:131-148.

Soemodihardjo, S., K. Kartawinata dan S. Prawiroatmodjo. 1977. Kondisi hutan payau di Teluk Jakarta dan pulau-pulau sekitarnya. Ose. Di Indon. 7:1-23.

Toro, V. 1990. Beberapa aspek ekologi udang windu, Penaeus monodon Fabricius di perairan mangrove Segara Anakan, Cilacap, Jawa Tengah Pros. Sem. IV Ekos. Mangrove. MAB-LIPI: 117-128. 
